\title{
Telomeric-Repeat Binding Factor
}

National Cancer Institute

\section{Source}

National Cancer Institute. Telomeric-Repeat Binding Factor. NCI Thesaurus. Code

C17775.

Human telomeric-repeat binding factor proteins (TRF) 1 and 2 are involved in the control of telomere dynamics in vivo. Reduced expression of TRF1 and TRF2 mRNAs was observed in human malignant hematopoietic and acute leukemia cell lines. However, expression of TRF1 and TRF2 mRNAs increased during differentiation of malignant hematopoietic cell line when induced artificially. Furthermore, studies from gastrointestinal carcinogenesis suggested that down-regulation of the TRF1 expression in tumor cells may be involved in cell immortalization. Together with hTERT, TRF1 and TRF2 are important regulators of telomerase activity and represent potential targets for cancer therapy. 